\title{
Giampiero Marzi, Gli oggetti di Flaubert
}

\section{Maria Emanuela Raffi}

\section{(2) OpenEdition}

\section{Journals}

\section{Edizione digitale}

URL: https://journals.openedition.org/studifrancesi/21536

DOI: 10.4000/studifrancesi.21536

ISSN: 2421-5856

\section{Editore}

Rosenberg \& Sellier

\section{Edizione cartacea}

Data di pubblicazione: 1 décembre 2019

Paginazione: 597

ISSN: 0039-2944

\section{Notizia bibliografica digitale}

Maria Emanuela Raffi, «Giampiero Marzi, Gli oggetti di Flaubert», Studi Francesi [Online], 189 (LXIII | III) | 2019, online dal 01 mars 2020, consultato il 11 novembre 2021. URL: http://journals.openedition.org/ studifrancesi/21536 ; DOI: https://doi.org/10.4000/studifrancesi.21536

Questo documento è stato generato automaticamente il 11 novembre 2021.

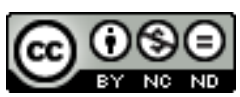

Studi Francesi è distribuita con Licenza Creative Commons Attribuzione - Non commerciale - Non opere derivate 4.0 Internazionale. 


\title{
Giampiero Marzi, Gli oggetti di Flaubert
}

\author{
Maria Emanuela Raffi
}

\section{NOTIZIA}

Giampiero Marzi, Gli oggetti di Flaubert, Roma, Empiria, 2017/18, 133 pp.

1 Toccando con leggerezza alcuni snodi fondamentali della storia e della cultura moderne - le origini della Rivoluzione francese, la nascita del realismo e i suoi rapporti con il romanticismo - e lo stesso tema degli oggetti in letteratura e in Flaubert, sul quale pesano studi come quelli di Stefano Agosti e Francesco Orlando, il saggio di Marzi si pone fin dall'inizio in una prospettiva non strettamente specialistica, come mostrano anche le citazioni sempre in italiano, tratte quindi da traduzioni, e la ripresa letterale di alcune formule flaubertiane, sulle quali la critica ha fornito numerosi approfondimenti, a partire dalla dichiarazione di voler fare «un livre sur rien» o dall'altrettanto dichiarato odio per il realismo. Sul rapporto di Flaubert con gli oggetti, specifico argomento di questo studio, l'A. propone un agile percorso fra il critico e l'aneddotico, costruito in buona parte sulla corrispondenza flaubertiana e su un intreccio fra analisi oggettiva e materia biografica. Concentrato sostanzialmente sull'abbigliamento in Madame Bovary - il berretto di Charles, i vestiti di Emma -, ricco di oggetti più variegati e spesso esterni (il cibo, i mobili, le facciate dei palazzi) nell'Éducation sentimentale, tutto costruito su ricordi di infanzia e su oggetti feticcio in Un cour simple, il mondo oggettuale flaubertiano tracciato da Marzi presenta una precisa evoluzione dal "romanzo della distruzione" al "libro su niente", al "romanzo della dissoluzione". Si tratta senza dubbio di una lettura gradevole, libera nella sua strutturazione e frutto di un intento quasi narrativo più che analitico. 